Article

\title{
Coralline-like $\mathrm{Ni}_{2} \mathrm{P}$ decorated novel tetrapod-bundle $\mathrm{Cd}_{0.9} \mathrm{Zn}_{0.1} \mathrm{~S}$ ZB/WZ homojunctions for highly efficient visible-light photocatalytic hydrogen evolution
}

\author{
Zhuwang Shao a, Xiao Meng a, Hong Lai a, Dafeng Zhang a, Xipeng $\mathrm{Pu}^{\mathrm{a}}{ }^{\text {,* }}$, Changhua Su ${ }^{\text {a }}$, Hong Li a, \\ Xiaozhen Ren a, Yanling Geng b \\ a School of Materials Science and Engineering, Shandong Provincial Key Laboratory of Chemical Energy Storage and Novel Cell Technology, Liaocheng \\ University, Liaocheng 252000, Shandong, China \\ b State Key Laboratory Base of Eco-chemical Engineering, College of Chemistry and Molecular Engineering, Qingdao University of Science and Technology, \\ Qingdao 266042, Shandong, China
}

\section{A R T I C L E I N F}

\section{Article history:}

Received 20 May 2020

Accepted 28 June 2020

Published 5 March 2021

\section{Keywords:}

Photocatalytic hydrogen evolution

$\mathrm{Cd}_{0.9} \mathrm{Zn}_{0.1} \mathrm{~S}$

$\mathrm{Ni}_{2} \mathrm{P}$

Homojunctions

Noble-metal-free

\begin{abstract}
A B S T R A C T
In this study, $\mathrm{Ni}_{2} \mathrm{P}-\mathrm{Cd}_{0.9} \mathrm{Zn}_{0.1} \mathrm{~S}$ (NPCZS) composites were synthesized by coupling tetrapod bundle $\mathrm{Cd}_{0.9} \mathrm{Zn}_{0.1} \mathrm{~S}(\mathrm{CZS})$ and coralline-like $\mathrm{Ni}_{2} \mathrm{P}(\mathrm{NP})$ via a simple calcination method. CZS shows outstanding activity in photocatalytic hydrogen evolution (1.31 $\left.\mathrm{mmol} \mathrm{h}^{-1}\right)$, owing to its unique morphology and heterophase homojunctions (ZB/WZ), which accelerate the separation and transfer of photogenerated charges. After coupling with NP, the photoactivity of NPCZS was enhanced, and the maximum hydrogen evolution rate of $1.88 \mathrm{mmol} \mathrm{h}^{-1}$ was reached at a NP content of $12 \mathrm{wt} \%$, which was 1.43 times higher than that of pure CZS. The experimental results of the photocatalytic activity, viz. photoluminescence spectra, surface photovoltage spectra, and electrochemical test showed that the enhanced photoactivity of NPCZS should be attributed to the synergistic effects of the novel tetrapod-bundle morphology, heterophase homojunctions, and decoration of the NP co-catalyst. Moreover, the as-prepared NPCZS composites exhibited excellent photostability and recyclability. Herein, we propose a possible mechanism for the enhanced photocatalytic activity.
\end{abstract}

(C) 2021, Dalian Institute of Chemical Physics, Chinese Academy of Sciences. Published by Elsevier B.V. All rights reserved.

\section{Introduction}

Today, the implementation of eco-friendly methods for energy production is vital because the exhaustion of fossil fuels and environmental pollution are becoming increasingly prominent problems [1-6]. Photocatalytic splitting of water into hydrogen gas $\left(\mathrm{H}_{2}\right)$ over semiconductors is one of the most promising approaches to overcome the challenges of energy and environment [7-11].

So far, numerous semiconductors have been extensively in- vestigated as photocatalysts. Among them, metal sulfides have attracted considerable attention attributed to their suitable band structure and effective performance in the photocatalytic hydrogen evolution reaction (HER) under visible-light irradiation $[12,13]$. The catalytic activities of materials are closely related to their morphology [14-16]. The morphology influences the separation and transfer of photogenerated charges and band gap structure, impacting the photocatalytic activity of the material. Consequently, various morphologies of metal sulfides, such as nanorods [17,18], hollow nanorods [19], nan-

\footnotetext{
* Corresponding author. Tel: +86-635-8230915; E-mail: xipengpu@hotmail.com 
owires [16,20], quantum dots [21,22] and nanosheets [23], have been investigated in the field of the photocatalytic HER. However, tetrapod metal sulfides with cubic zinc blende (ZB) and hexagonal wurtzite (WZ) structures have seldom been reported. Therefore, we synthesized a tetrapod bundle

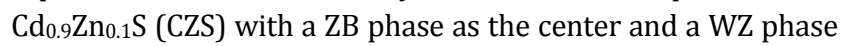
as the arms, based on the pioneering research of Xue et al. [24]. In addition, the arms had a new morphology compared to those of previous reports, which was a bundle structure composed of numerous nanorods. Moreover, the tetrapod bundle showed extremely high photocatalytic HER activity. Based on previous research, we considered that the high catalytic performance of the composite might be due to the formation of an electrostatic field between the ZB/WZ heterophase and its unique morphology, which could accelerate the separation and transfer of photogenerated charges $[15,25]$. Further, we studied the photocatalytic HER activity of the composite under different morphologies by destroying its tetrapod-bundle structure to various degrees and proposed a possible mechanism for its enhanced activity.

Generally, adding a co-catalyst to the photocatalyst can effectively improve its performance in the photocatalytic HER. Noble metals as co-catalysts can attract and trap photogenerated electrons easily and act as the active center of a $\mathrm{H}^{+}$reduction reaction [26]; numerous kinds of noble metals and their related compounds have been widely investigated, such as $\mathrm{Pt}$ [27], Pd [28], Ru [29], Ag [30], and PdS [31]. However, noble metals are scarce and high-cost, which limit their large-scale commercial applications. Thereby, it is necessary and urgent to develop low-cost and high-efficiency co-catalysts using abundant elements. Effective HER electrocatalysts can act as co-catalysts in the photocatalytic HER. In this regard, transition-metal phosphides (TMPs), such as CoP [32], $\mathrm{Co}_{2} \mathrm{P}$ [33], MoP [34], and $\mathrm{Cu}_{3} \mathrm{P}$ [35] have higher potential as electrocatalysts due to their low cost, outstanding catalytic activity, and stability for the HER [36,37]. Researchers have confirmed that the above electrocatalysts can effectively enhance the photocatalytic HER activity as co-catalysts [38-42]. Consequently, we believe that this strategy for finding photocatalytic co-catalysts from TMPs is feasible. Compared to other TMP co-catalysts mentioned above, $\mathrm{Ni}_{2} \mathrm{P}$ (NP) has many attractive advantages, such as high photocatalytic HER activity and stronger stability $[43,44]$. Additionally, the reported morphologies of NP are only nanoparticles $[44,45]$; there are no reports of other morphologies. Based on the above analysis, we prepared a new coralline-like NP via a hydrothermal process and used it as a co-catalyst; to the best of our knowledge, this morphology is the first reported.

In this study, $\mathrm{Ni}_{2} \mathrm{P}-\mathrm{Cd}_{0.9} \mathrm{Zn}_{0.1} \mathrm{~S}$ (NPCtZS) photocatalysts were successfully synthesized and used in the photocatalytic HER under visible-light irradiation. Specifically, CZS and NP showed novel tetrapod-bundle and coralline-like morphologies, respectively. The morphology, structure, optical properties, and electrochemical characterizations of the NPCZS photocatalysts were studied in detail. The tetrapod-bundle CZS showed outstanding photocatalytic HER activity, which was further promoted after loading the NP co-catalyst. The possible mecha- nisms for the photocatalytic activity over pristine CZS and NPCZS composites are proposed. This work demonstrates that the morphology of the catalyst exerts a strong influence on the photocatalytic HER activity, and the coralline-like NP is an effective co-catalyst.

\section{Experimental}

\subsection{Synthesis of the NPCZS composites}

All chemicals (Aladdin Chemical Reagent Co., Ltd.) were of analytical grade and used as received without further purification.

The CZS was prepared via a hydrothermal method. Firstly, 1 mmol zinc acetate $\left(\mathrm{Zn}(\mathrm{OAc})_{2} \cdot 2 \mathrm{H}_{2} \mathrm{O}\right)$ and $9 \mathrm{mmol}$ cadmium acetate $\left(\mathrm{Cd}(\mathrm{OAc})_{2} \cdot 2 \mathrm{H}_{2} \mathrm{O}\right)$ were dissolved in $30 \mathrm{~mL} \mathrm{H} \mathrm{H}_{2} \mathrm{O}$; then, 30 $\mathrm{mL}$ ethylenediamine was added and stirred for $10 \mathrm{~min}$. Subsequently, $12.5 \mathrm{mmol}$ of thioacetamide was added. After vigorous stirring for $10 \mathrm{~min}$, the mixed solution was transferred into a $100 \mathrm{~mL}$ Teflon-lined stainless-steel autoclave and maintained at $220^{\circ} \mathrm{C}$ for $24 \mathrm{~h}$. The products were collected, washed several times with water and absolute ethanol, and dried at $60^{\circ} \mathrm{C}$ for 8 h.

For the synthesis of NP, $2 \mathrm{mmol}$ nickel chloride hexahydrate $\left(\mathrm{NiCl}_{2} \cdot 6 \mathrm{H}_{2} \mathrm{O}\right)$ was dissolved in $40 \mathrm{~mL}$ ethylene glycol under vigorous stirring for $15 \mathrm{~min}$ at room temperature. Thereafter, red phosphorus (6 mmol) was added and stirred until homogenization. Afterward, the above suspension was transferred into a $100 \mathrm{~mL}$ Teflon-lined stainless-steel autoclave, which was sealed and maintained at $200{ }^{\circ} \mathrm{C}$ for $14 \mathrm{~h}$. When the autoclave cooled to room temperature, the products were collected, washed several times with water and absolute ethanol, and dried at $60^{\circ} \mathrm{C}$ for $8 \mathrm{~h}$.

Finally, NPCZS composites were prepared via a calcination method; the schematic illustration for the fabrication of NPCZS is depicted in Fig. 1. The as-prepared NP was placed in mortar with absolute ethanol and was ground for $40 \mathrm{~min}$ to fine powder for future use. Then, an appropriate amount of NP and CZS was added into $20 \mathrm{~mL}$ of acetone followed by ultrasonic treatment $(150 \mathrm{~W})$ with $50 \%$ power for $30 \mathrm{~min}$. After the residual acetone evaporated naturally, the products were calcined at $180{ }^{\circ} \mathrm{C}$ for $2 \mathrm{~h}$ with a ramp of $6^{\circ} \mathrm{C}$ per minute. The weight ratios of NP to CZS were $5 \%, 8 \%, 12 \%, 15 \%$, and $20 \%$, which were labeled as NPCZS-5, NPCZS-8, NPCZS-12, NPCZS-15, and NPCZS-20, respectively.

\subsection{Characterizations}

X-ray powder diffraction (XRD) patterns were obtained using a diffractometer (D8 Advanced, Bruker Co., Germany) with $\mathrm{Cu}-K_{\alpha}(\lambda=0.15418 \mathrm{~nm})$ operated at $40 \mathrm{kV}$ and $30 \mathrm{~mA}$. The morphologies and structures of the samples were evaluated via scanning electron microscopy (SEM) using a Gemini microscope (Zeiss Ltd., Germany) at an accelerating voltage of $2 \mathrm{kV}$, equipped with an energy-dispersive X-ray spectrometer (EDS), and transmission electron microscopy (TEM) using a JEM-2100 microscope (JEOL Ltd., Japan). X-ray photoelectron spectros- 


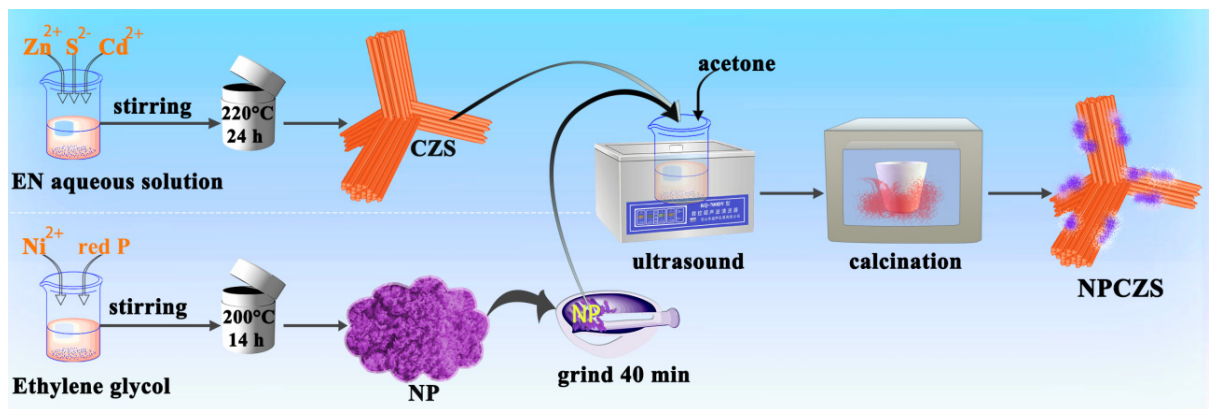

Fig. 1. Schematic of the fabrication procedure of NPCZS.

copy (XPS) was performed with an ESCALAB250 X-ray photoelectron spectrometer (Thermo-VG Scientific, USA) with monochromatic $\mathrm{Al} \mathrm{K-} \alpha 1.2$ radiation $(E=1486.60 \mathrm{eV})$. Photoluminescence (PL) spectra were obtained with an F-7000 spectrometer (Hitachi Ltd., Japan). UV-vis diffuse reflectance spectra (DRS) were taken with a UV-3600 spectrophotometer (Shimadzu, Japan). Time-resolved photoluminescence (TRPL) spectra were obtained with an Edinburgh fluorescence and phosphorescence spectrometer (FLS 920, UK). Surface photovoltage (SPV) spectra were recorded with a surface photovoltage spectrometer (PL-SPS/IPCE1000 Beijing Perfect Light Technology Co., China). The composition was determined using a $2100 \mathrm{DV}$ inductively coupled plasma-atomic emission spectrometer (ICP-AES, Perkin Elmer, USA).

\subsection{Electrochemical measurements}

The electrochemical tests were performed using a standard three-electrode system with a 660 D electrochemical workstation (Chenhua Co., China). The working electrode was prepared by placing $50 \mu \mathrm{L}$ slurry composition of $30 \mathrm{mg}$ of catalyst and $2 \mathrm{~mL}$ of isopropanol onto a $0.5 \mathrm{~cm} \times 0.5 \mathrm{~cm}$ fluorine-doped tin oxide glass, which was then dried at $80{ }^{\circ} \mathrm{C}$ for $5 \mathrm{~h}$. The photocurrent measurements, electrochemical impedance spectra (EIS), and Mott-Schottky (M-S) data were obtained in a $\mathrm{Na}_{2} \mathrm{SO}_{4}$ $(0.1 \mathrm{M})$ aqueous solution under irradiation with a $300 \mathrm{~W}$ xenon lamp (CEL-HXF300, Ceaulight Co., China).

\subsection{Photocatalytic measurement}

The photocatalytic production of hydrogen was performed in a closed circulation system (CEL-SPH2N-D9, Beijing China Education $\mathrm{Au}$-light $\mathrm{Co}$.) under a 300-W xenon lamp, equipped with $400 \mathrm{~nm}$ cut-off filters, and the active area of the reaction was approximately $16 \mathrm{~cm}^{2}$. In a typical manner, $20 \mathrm{mg}$ of catalyst was well-dispersed in $100 \mathrm{~mL}$ sacrificial reagents $(0.7 \mathrm{M}$ $\mathrm{Na}_{2} \mathrm{~S}$ and $0.5 \mathrm{M} \mathrm{Na}_{2} \mathrm{SO}_{3}$ ). The system was vacuumed before the xenon lamp was turned on. The amount of generated hydrogen was measured via gas chromatography (GC-7900) with a thermal conductivity detector. In addition, the average $\mathrm{H}_{2}$ evolution rates were calculated based on the amount of hydrogen produced in the first $3 \mathrm{~h}$ of the reaction.

The apparent quantum efficiency (AQE) was measured at $420 \mathrm{~nm}( \pm 5 \mathrm{~nm})$ using a $420 \mathrm{~nm}$ band-pass filter.

$$
\begin{gathered}
\mathrm{AQE}(\%)=\frac{\text { number of evolved hydrogen molecules } \times 2}{\text { number of incident photons }} \times 100 \% \\
=2 \mathrm{CN}_{\mathrm{A}} /\left(\mathrm{S}_{\mathrm{P}} \lambda / h c\right) \times 100 \%
\end{gathered}
$$

where $C, S, t, N_{\mathrm{A}}, P, h, \lambda$, and $c$ are the $\mathrm{H}_{2}$ production amount, irradiation area, photocatalytic reaction time, Avogadro constant, monochromatic light intensity $\left(48.5 \mathrm{mw} / \mathrm{cm}^{2}\right.$, detected with an optical power meter), Planck constant, wavelength of monochromatic light, and speed of light, respectively.

\section{Results and discussion}

\subsection{Physicochemical properties}

Fig. 2(a) shows the XRD pattern of CZS. The major diffraction peaks of pristine CZS were almost consistent with those of the hexagonal WZ phase CdS (WZ-CdS, JCPDS No. 80-0006). Moreover, the diffraction peaks of CZS shifted toward higher degrees; this shift was attributed to the doping of $\mathrm{Zn}^{2+}$ ions to the CdS lattice precipitating a decreased interplanar spacing. Apart from the peaks of the hexagonal WZ phase, some representative peaks at approximately $30.8^{\circ}$ and $64.2^{\circ}$ can be observed, corresponding to the (200) and (400) diffraction facets of the cubic ZB phase (ZB-CdS, JCPDS No. 80-0019). The above results indicate that the WZ and ZB coexisted in CZS. The XRD pattern of pure NP can be indexed to that of the hexagonal NP (JCPDS No. 74-1385); its intense and sharp diffraction peaks suggest it has high crystallinity, as shown in Fig. 2(b). The diffraction peaks of CZS showed no change after coupling with NP, which implied that NP did not influence the lattice structure of CZS. Moreover, the diffraction peaks of the NP phase were not obvious until the NP content was as high as $15 \mathrm{wt} \%$, because of the low content of NP on the surface of CZS.

The morphologies of the as-prepared CZS, NP, and NPCZS composites were studied with SEM in detail, as shown in Fig. 3. CZS appears in the form of a tetrapod bundle (Fig. 3(a) and (b)), composed by a ZB center and WZ arms with an average length of 1.2-1.8 $\mu \mathrm{m}$ and diameter of $\sim 80 \mathrm{~nm}$. As shown in Fig. 3(c), the morphology of NP is similar to that of sea corals (inset photo). Fig. 3(d) shows that the NP is a multilevel structure composed of nanosheets. Concerning the NPCZS-12 sample in Fig. 3(e), NP is attached on the surface of CZS, and CZS retains the original tetrapod-bundle morphology. Moreover, the EDS spectrum and elemental mapping of NPCZS-12 are depicted in Fig. 3(f). As expected, $\mathrm{Cd}, \mathrm{Zn}, \mathrm{S}, \mathrm{Ni}$, and $\mathrm{P}$ can be found in the 

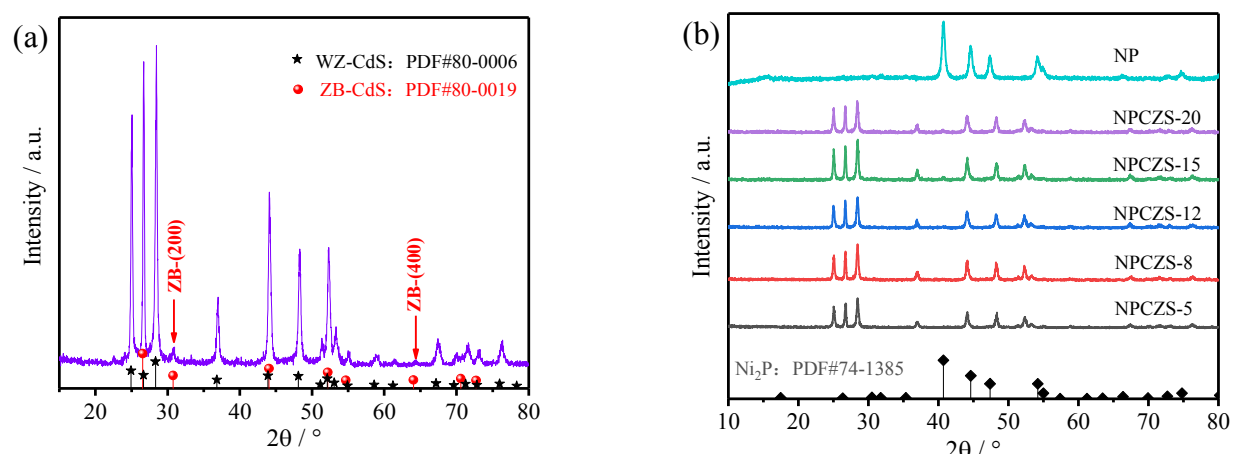

Fig. 2. XRD patterns of CZS (a) and NP and NPCZS composites (b).
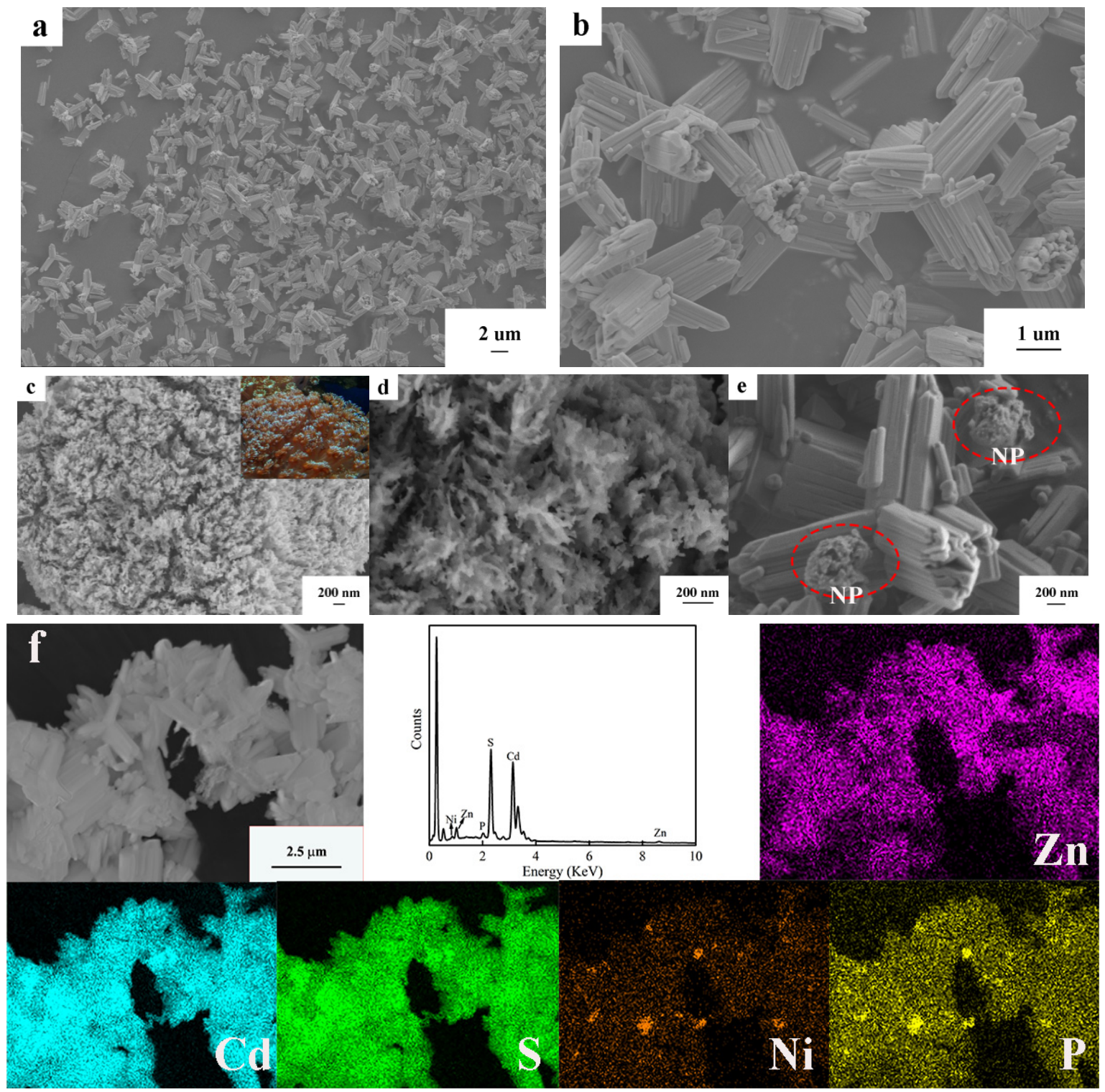

Fig. 3. SEM images of CZS (a,b), NP (c,d), and NPCZS-12 (e); (f) EDS spectrum and EDS mapping for different elements of NPCZS-12.

EDS spectrum, and the distribution profiles of elements demonstrate that the NPCZS composites were constructed successfully. In addition, the composition of NPCZS-12 was evaluated with ICP-AES. The average $\mathrm{Ni} /(\mathrm{Cd}+\mathrm{Zn})$ molar ratio was $0.225 \pm 0.02$, which was consistent with the expected stoichiometric ratio.

In order to understand the microstructure details of CZS and NPCZS in-depth, the composites were characterized with TEM 
and HRTEM. In Fig. 4(a), the TEM image of CZS shows a branched morphology, which is in accordance with the SEM observations. As shown in the right region of Fig. 4(b), the lattice distance of three kinds of lattice fringes is $0.33 \mathrm{~nm}$, which belongs to $\{111\}$ facets of the ZB phase. This observation further confirms the existence of a ZB structure, which is in accordance with our XRD observations. However, the left region of Fig. 4(b) shows that the lattice distance is also $0.33 \mathrm{~nm}$, but the lattice fringes are different from the previous and can be attributed to a (0002) crystal plane of the WZ phase. Moreover, the interfaces between the ZB and WZ phases are apparent, implying that the lattice-matched planes between $\mathrm{ZB}$ and $\mathrm{WZ}$ have an epitaxial relationship. Furthermore, Fig. 4(c) depicts the TEM image of the CZS arm region; its lattice distance is 0.33 $\mathrm{nm}$, which is indexed to the (0002) crystal plane of the WZ phase, and confirms that the structure of the CZS arms regions is WZ. In addition, the phase structure and morphologies of different reaction times of CZS were characterized to comprehend the growing process of tetrapod-bundle CZS (Fig. S1). When the reaction time was approximately $5 \mathrm{~h}$, the XRD pattern exhibited the diffraction peaks of the ZB phase of CZS. Meanwhile, the tetrapod-bundle structure began to form, and the arms of CZS gradually grew through swallowing the small particles. Therefore, the ZB phase nucleated in the growing process of the tetrapod-bundle CZS and was followed by the growth of WZ arms along the four equivalent $\{111\}$ facets of the ZB core; this is consistent with other reports $[24,46]$. Finally, the morphology of CZS became a tetrapod bundle. Therefore, the ZB and WZ structures occupied the center and arm region of CZS, respectively.

In addition, as shown in Fig. 4(d,e), NP was attached to the surface of CZS, and the lattice distances of $0.22 \mathrm{~nm}$ and $0.33 \mathrm{~nm}$ can be well indexed to the $\{111\}$ crystal plane of NP and (0002) crystal plane of CZS, respectively, which indicates that the NPCZS composite was successfully constructed.
The surface chemical states of elements in CZS, NP, and NPCZS-12 were investigated with XPS measurements, as shown in Fig. 5. The XPS survey spectrum of NPCZS-12 confirmed that $\mathrm{Cd}, \mathrm{Zn}, \mathrm{S}, \mathrm{Ni}$, and $\mathrm{P}$ were present, as shown in Fig. 5(a). Figure 5(b-d) shows that the $\mathrm{Zn} 2 p$, Cd $3 d$, and S $2 p$ peaks of NPCZS-12 slightly shift toward higher binding energies in comparison to those of the pure CZS. Figure 5(e,f) shows the high-resolution XPS spectra of Ni $2 p$ and P $2 p$ in NP and NPCZS-12. For NP, the Ni $2 p$ peaks at 853.3 and $856.6 \mathrm{eV}$ were assigned to $\mathrm{Ni}^{\delta+}$ of NP and surface oxidation states [47]; the $\mathrm{Ni}$ $2 p$ peak of NPCZS-12 is negatively shifted compared to that of NP. Moreover, the peaks of P $2 p$ of NP at 129.6 and $132.9 \mathrm{eV}$ were attributed to $\mathrm{P}^{\delta-}$ of metal and oxidized phosphide species owing to surface oxidation [48]. Furthermore, the binding energy shifts of these elements (Zn, Cd, S, and Ni) suggest a strong interaction between CZS and NP, resulting in the effective migration of electrons from CZS to NP.

The DRS of the as-prepared CZS, NP, and NPCZS composites were recorded to characterize their optical absorption properties, as shown in Fig. 6. The pristine CZS displayed intense absorption in the UV-vis range with an abrupt decrease at $\sim 510$ $\mathrm{nm}$, which informs about the band gap. The absorption edge of CZS was not shifted in the DRS of the NPCZS composites, but light absorption was remarkably enhanced in the visible region, indicating that the loading of NP on the surface of CZS was beneficial for light absorption. In addition, the band gap of CZS was determined at approximately $2.42 \mathrm{eV}$ from the Tauc plot, as shown in the inset.

\subsection{Photocatalytic $\mathrm{H}_{2}$ evolution performances}

As shown in Fig. 7(a), the photocatalytic activity curves of the NPCZS composites increased linearly with time. The $\mathrm{H}_{2}$ evolution rate first increased and then decreased with increasing NP content, and NPCZS-12 had the highest activity with an

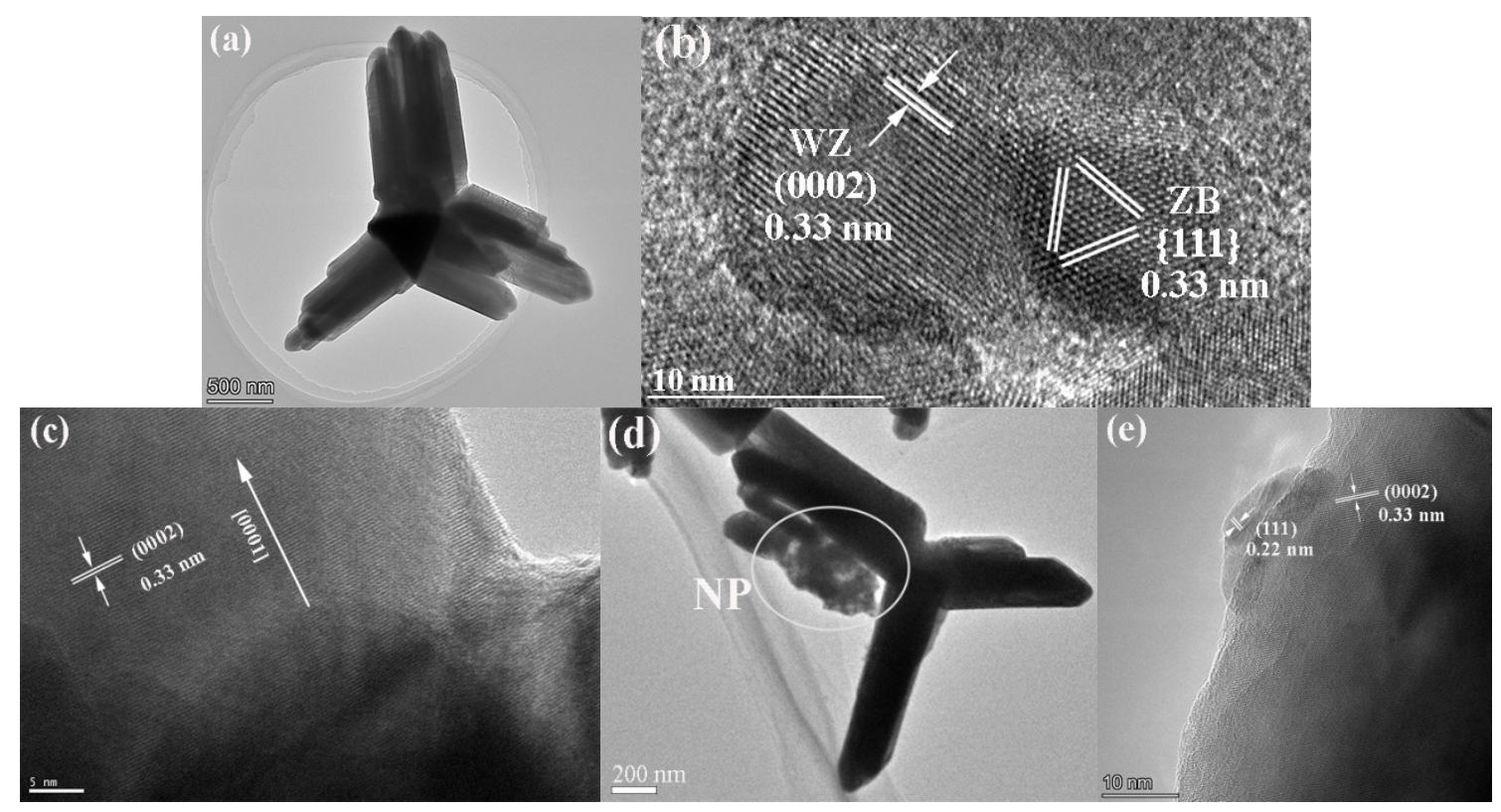

Fig. 4. (a) TEM and (b) HRTEM images of CZS; (c) TEM image of CZS arm; (d) TEM and (e) HRTEM images of NPCZS composite. 

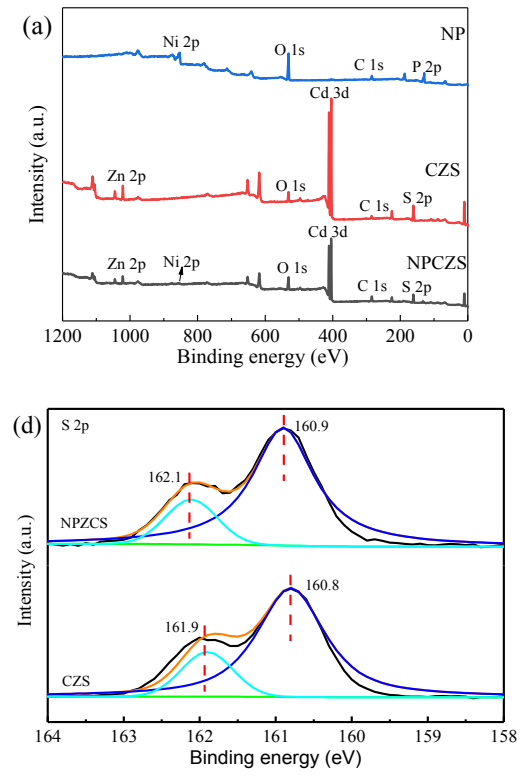
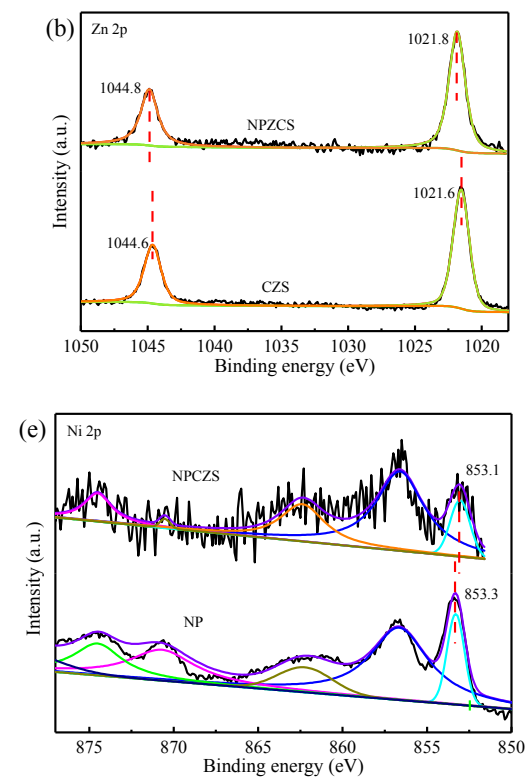
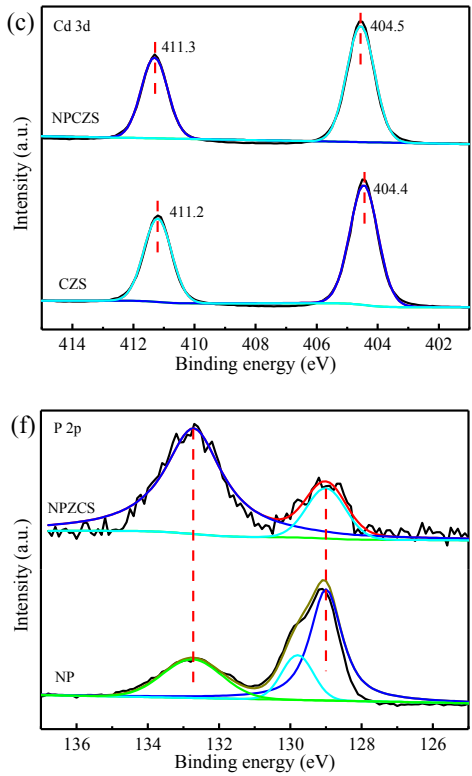

Fig. 5. Survey spectra (a) and high-resolution XPS spectra (b-f) of Zn $2 p$, Cd $3 d, \mathrm{~S} 2 p$, Ni $2 p$, and P $2 p$.

average rate of $1.88 \mathrm{mmol} \mathrm{h}^{-1}$ (Fig. 7(b)), which was approximately 1.57 times higher than that of CZS-U50 (1.19 $\left.\mathrm{mmol} \mathrm{h}^{-1}\right)$ (the preparation procedure of CZS-U50 is in the Supplemental Information,) and the AQE reached $62.3 \%$ at $420 \mathrm{~nm}$.

For application purposes, the recyclability of the NPCZS-12 photocatalyst was further investigated via a photocatalysis experiment for $48 \mathrm{~h}$, in which the photocatalytic activity showed no decrease, as shown in Fig. 7(c). In addition, a series of $\mathrm{Ni}_{2} \mathrm{P}-\mathrm{ZnS}$ and $\mathrm{Ni}_{2} \mathrm{P}-\mathrm{CdS}$ composites were prepared and used in the photocatalytic HER to study the effect of NP alongside metal sulfides. The preparation procedure of the $\mathrm{Ni}_{2} \mathrm{P}-\mathrm{ZnS}$ and $\mathrm{Ni}_{2} \mathrm{P}-\mathrm{CdS}$ composites is described in the Supplemental Information. As Fig. S2 depicts, the yield of photocatalytic HER after $3 \mathrm{~h}$ suggested that NP can significantly improve the photocatalytic activity of both $\mathrm{ZnS}$ and $\mathrm{CdS}$, which implies that NP is a potential co-catalyst.

To demonstrate the effect of the morphology of this novel tetrapod bundle on its performance in the photocatalytic HER,

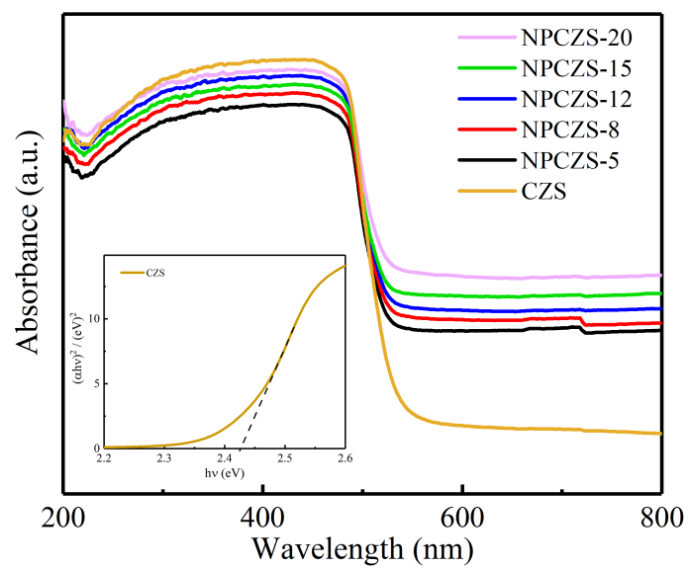

Fig. 6. UV-vis DRS of CZS, NP, and NPCZS composites; inset shows Tauc plots of $(\alpha h v)^{2}$ over hv of CZS. the morphology of a pristine tetrapod-bundle CZS was destroyed to different degrees via applying $50 \%$ power ultrasonic (CZS-U50), 100\% power ultrasonic (CZS-U100) and mechanical grinding (CZS-G). The experimental procedure for the destruction of the morphology, related characterizations, and description are in the Supplemental Information and Fig. S3, respectively. We evaluated the photocatalytic HER activity of these samples (Fig. 8(a,b)), which gradually decreased with the increasing damage to the morphology of CZS. The pristine CZS had the highest photocatalytic activity of $1.31 \mathrm{mmol} \mathrm{h}^{-1}$, which was approximately 2.6 times higher than that of CZS-G $(0.49$ $\mathrm{mmol} \mathrm{h}^{-1}$ ). This result indicated that the novel tetrapod-bundle morphology of CZS influenced the photocatalytic activity. The photocatalytic activity of CZS-U50 was not significantly lower than that of CZS because of a relatively complete morphology.

\subsection{Possible photocatalytic mechanism}

The separation and transfer of photogenerated charges by NPCZS composites were investigated with PL spectroscopy, photocurrent experiments, SPV spectroscopy, and EIS. The PL emission intensity of NPCZS composites was weaker than that of the pristine CZS at the position of the intrinsic band gap emission, indicating that the recombination of photogenerated charges was restrained (Fig. 9(a)). As presented in Fig. 9(b), a considerable increase in the transient photocurrent responses for the NPCZS composites indicated that electrons could be rapidly excited, transferred, and form a photocurrent under light irradiation more easily than pristine CZS. In addition, the enhancement of photocurrent responses suggested that the loading of NP on the surface of CZS was favorable to the extraction of electrons, resulting in highly effective charge separation [49]. As shown in Fig. 9(c), the photovoltage response for CZS was positive from $300 \mathrm{~nm}$ to $550 \mathrm{~nm}$, indicating that CZS is an 

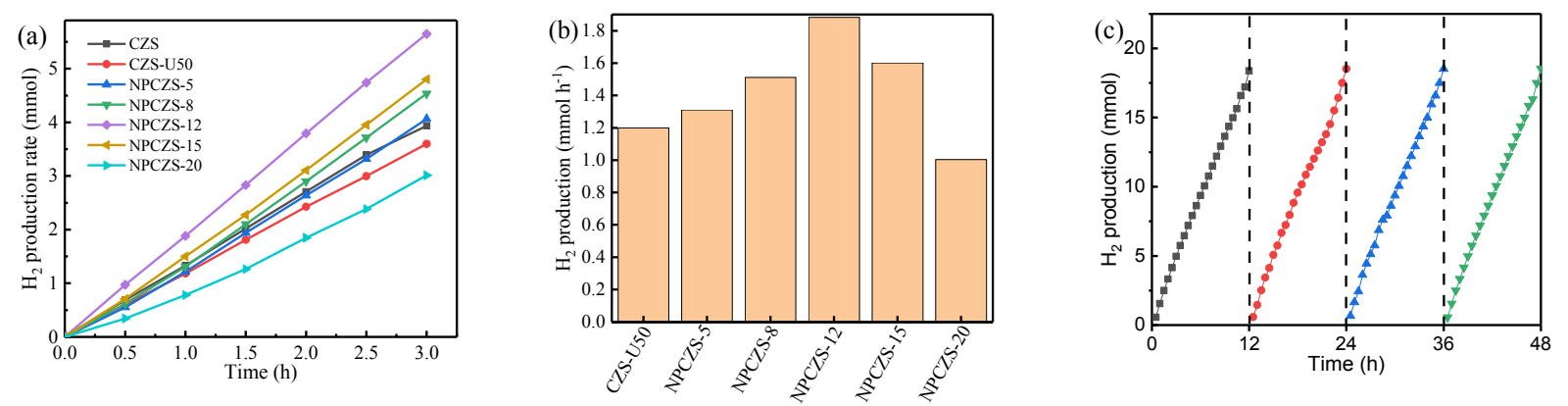

Fig. 7. Time-dependent photocatalytic $\mathrm{H}_{2}$ evolution (a) and average $\mathrm{H}_{2}$ production rates (b) of as-obtained samples under visible-light irradiation; (c) curves for photocatalytic $\mathrm{H}_{2}$ evolution cycling of NPCZS-12 under visible-light irradiation.
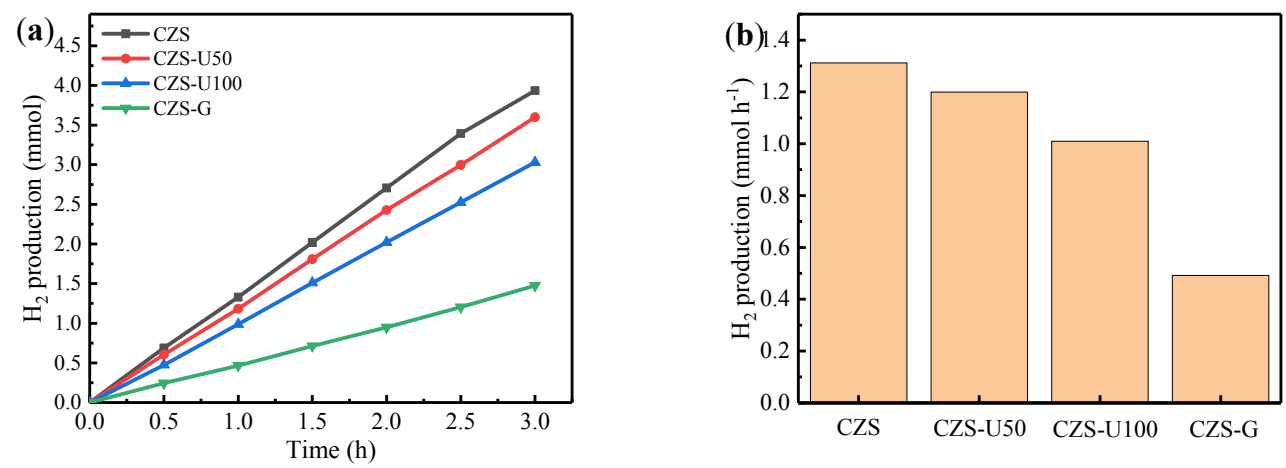

Fig. 8. Time-dependent photocatalytic $\mathrm{H}_{2}$ evolution (a) and average $\mathrm{H}_{2}$ production rates (b) of CZS, CZS-U50, CZS-U100, and CZS-G under visible-light irradiation.

n-type semiconductor [47]. The photovoltage of the NPCZS composites was enhanced compared to that of the pure CZS, indicating a more efficient separation of photogenerated charges in the NPCZS composites [50]. The EIS in Fig. 9(d) shows that the NPCZS composite exhibited a reduced radius of Nyquist plot compared to that of pristine CZS, indicating that the NPCZS composite had lower electronic resistance [51]. All these measurements confirm that the hybridization of CZS and NP can accelerate the separation and transfer of photogenerated charges compared to that of pristine CZS, which implies that NP can act as a collector of photogenerated electrons and prolong its lifetime, leading to enhanced photocatalytic HER activity.

To understand the influence of morphology on the photocatalytic HER activity in-depth, we performed SPV and TRPL spectroscopies to study the separation behavior and lifetime of photogenerated charges, and the possible mechanism is proposed. CZS presented a much higher SPV response than CZS-G, indicating that the photogenerated charges were separated more efficiently in CZS (Fig. S4(a)). The TRPL results showed that the photogenerated charges from CZS had a longer lifetime than those from CZS-G [Fig. S4(b)], which further confirmed the highly efficient separation of charges by pristine CZS, leading to an increase in the lifetime of charges. The WZ phase occupies a conduction band (CB) and valence band (VB) higher than its ZB counterpart $[15,24,25]$. Based on the above analysis, the possi- ble mechanism of the influence of morphology on the photocatalytic HER activity is proposed and illustrated in Fig. 10(a). According to the alignment of $\mathrm{CB}$ and VB potentials of $\mathrm{WZ}$ and ZB phases, a type-II homojunction is constructed between them. Under visible-light irradiation, the photogenerated electrons transfer from $\mathrm{CB}$ of the $\mathrm{WZ}$ phase to $\mathrm{CB}$ of the $\mathrm{ZB}$ phase, while holes migrate from $\mathrm{VB}$ of the $\mathrm{ZB}$ phase to $\mathrm{VB}$ of the $\mathrm{WZ}$ phase. Consequently, the photogenerated charges are separated effectively under the internal electrostatic field formed in the type-II junction region; thus, hydrogen is rapidly produced at the ZB phase. Furthermore, in comparison to heterojunctions formed by two or more semiconductors, the ordered type-II junction in one semiconductor not only retains the transfer characteristics of charges just as perfect nanocrystals because of its highly ordered structures but also effectively separates photoinduced charges and hinders their recombination. Conversely, the one-dimensional structure was favorable to the formation of a space charge region that transports the photogenerated charges along the longitude of the nanorod; consequently, the arms of CZS composed by nanorods are also significant to the acceleration of the directional transportation of the charges along the nanorod. In conclusion, the tetrapod-bundle CZS has the two advantages mentioned above compared to CZS with damaged morphology, resulting in higher charge separation efficiency and better photocatalytic performance. 

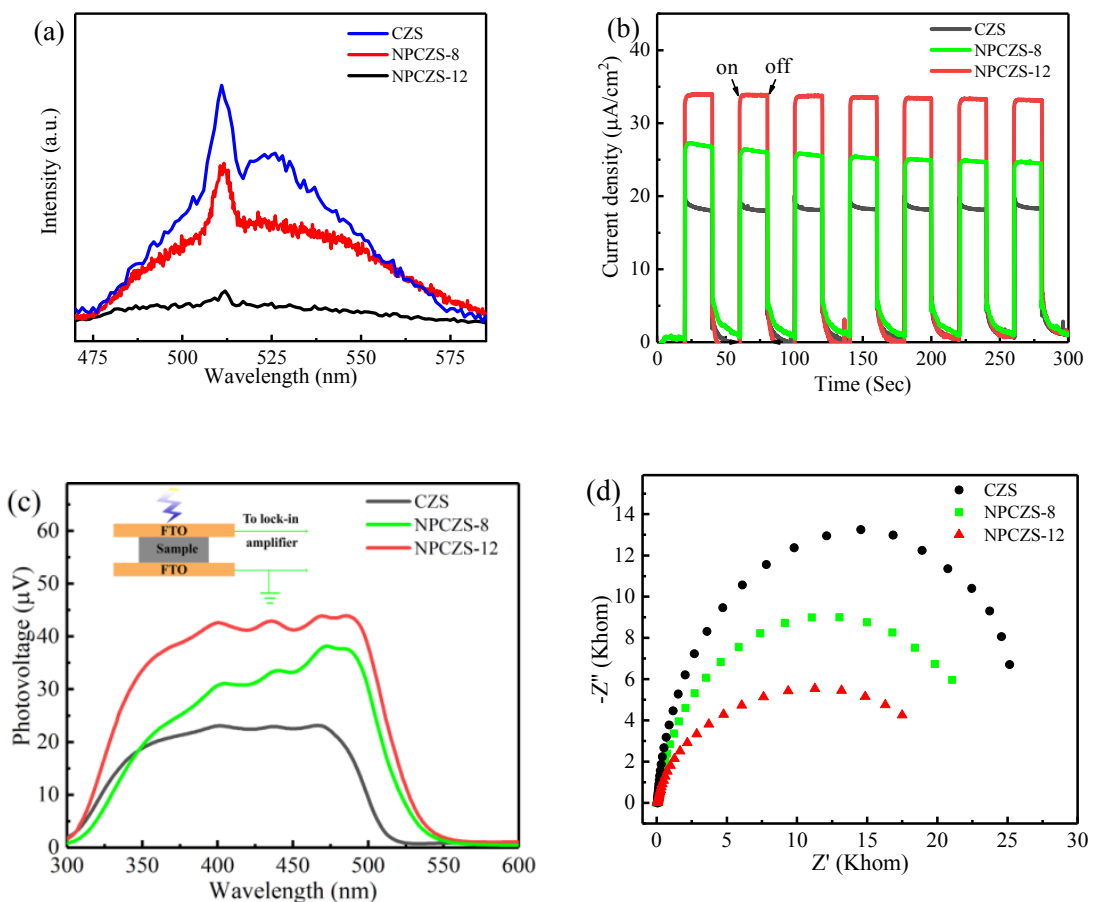

Fig. 9. PL spectra (a), transient photocurrent responses (b), SPV spectra (c) (inset shows the schematic setup for SPV measurement), and EIS (d) of CZS, NP, and NPCZS composites.
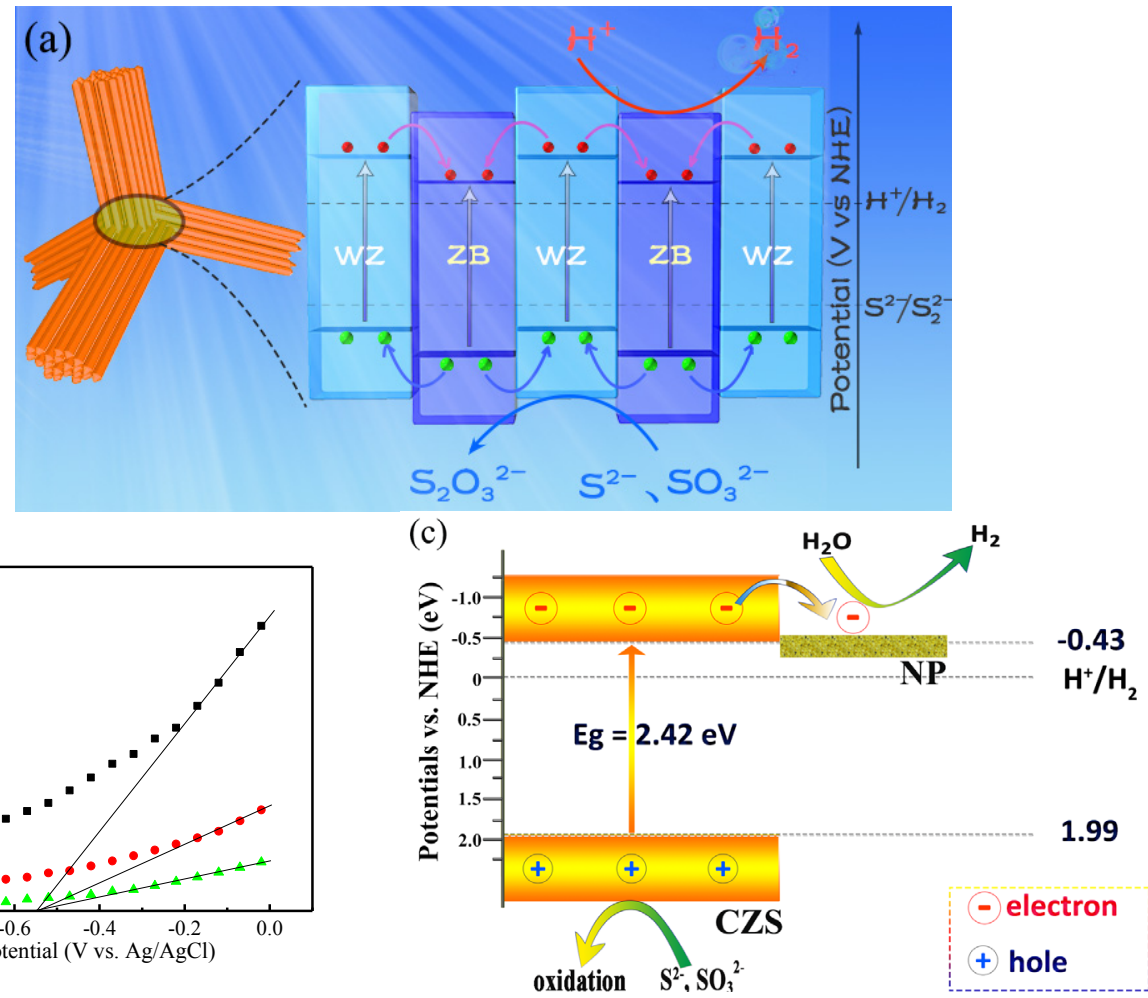

Fig. 10. (a) Mechanism of photogenerated charge separation of ZB/WZ homojunctions over CZS for the photocatalytic HER; (b) M-S plot of CZS; (c) photocatalytic mechanism of NPCZS under visible-light irradiation.

Further, the M-S plot was constructed at frequencies of 500 , 800 , and $1000 \mathrm{~Hz}$ in $0.1 \mathrm{M} \mathrm{Na}_{2} \mathrm{SO}_{4}$ solution at $\mathrm{pH}=7$ to better understand the energy-band structure of CZS, as shown in Fig. $10(\mathrm{~b})$. The M-S is an effective method to confirm the type and flat-band potential of semiconductors. The M-S plot of CZS is a positive slope, indicating that the CZS is an n-type semiconductor. Moreover, the flat-band potential of CZS can be confirmed by extrapolating the lines to $1 / \mathrm{C}^{2}=0$ and was determined to be $-0.53 \mathrm{~V}$ (vs. $\mathrm{Ag} / \mathrm{AgCl}$ at $\mathrm{pH}=7$ ). Generally, the $\mathrm{CB}$ potential is $0.1 \mathrm{~V}$ lower than that of the flat-band position for $n$-type semi- 
conductors; thus, the $\mathrm{CB}$ potential of CZS was $-0.63 \mathrm{~V}$ (vs. $\mathrm{Ag} / \mathrm{AgCl}$ at $\mathrm{pH}=7$ ). The conversion relationship between an $\mathrm{Ag} / \mathrm{AgCl}$ electrode and a normal hydrogen electrode (NHE) is $E_{\mathrm{NHE}}=E_{\mathrm{Ag} / \mathrm{AgCl}}+0.197$ [52], so $\mathrm{CB}$ and $\mathrm{VB}$ were -0.43 and 1.99 $\mathrm{eV}$ (vs. NHE), respectively. Based on the photocatalytic HER activity of the NPCZS composites and the above tests analyses, the possible mechanism for the photocatalytic activity of NPCZS composites was proposed, as depicted in Fig. 10(c). CZS generates electron-hole pairs under visible-light irradiation, and the electrons are excited to the CB. Afterward, electrons transfer rapidly to NP because it can act as an electron collector, and holes accumulate on the surface of CZS, which separates the electron-hole pairs effectively [44,47,53]. Regardless of CZS generating $\mathrm{H}_{2}$, the lower $\mathrm{H}_{2}$ adsorption energy of the NP surface favors the reduction of $\mathrm{H}^{+}$[54]; thus, NP acts as an active reaction center in the photocatalytic $\mathrm{H}_{2}$ evolution, and the coralline-like morphology of NP composed of nanosheets has a larger surface area; thus, it can provide a large number of active reaction sites, resulting in improved photocatalytic activity. Simultaneously, the holes are consumed by $\mathrm{Na}_{2} \mathrm{~S}$ and $\mathrm{Na}_{2} \mathrm{SO}_{3}$ sacrificial reagents.

\section{Conclusions}

A highly efficient and noble-metal-free NPCZS photocatalyst was successfully synthesized via a simple calcination method, and it retained the novel tetrapod-bundle morphology of CZS. Pristine CZS exhibited outstanding photocatalytic HER activity owing to the existence of ZB/WZ homojunctions and its unique morphology. In addition, the photocatalytic activity was improved after coupling with a NP co-catalyst; NPCZS-12 exhibited the highest average hydrogen evolution rate of $1.88 \mathrm{mmol}$ $\mathrm{h}^{-1}$, which was 1.43 times higher than that of the pure CZS.
Furthermore, the NPCZS-12 sample showed strong stability in recyclability experiments. Moreover, NP could effectively accelerate the separation and transfer of photogenerated charges and act as a reactive site to generate $\mathrm{H}_{2}$. This work demonstrated that the tetrapod-bundle morphology of CZS showed a remarkable photocatalytic HER activity, and that the coralline-like NP is a promising co-catalyst.

\section{References}

[1] S. Liang, T. Zhang, D. Zhang, X. Pu, X. Shao, W. Li, J. Dou, J. Am. Ceram. Soc., 2018, 101, 3424-3436.

[2] H. Zhou, J. Yin, Z. Nie, Z. Yang, D. Li, J. Wang, X. Liu, C. Jin, X. Zhang, T. Ma, J. Mater. Chem. A, 2016, 4, 67-73.

[3] B. Ge, L. Han, X. Liang, F. Li, X. Pu, X. Zhu, Z. Zhang, X. Shao, C. Jin, W. Li, Appl. Surf. Sci., 2018, 462, 583-589.

[4] S. Liang, D. Zhang, X. Yao, R. Han, Q. Zhang, C. Jin, X. Pu, Y. Geng, Sep. Purif. Technol., 2019, 116450.

[5] D. Zhang, C. Su, H. Li, X. Pu, Y. Geng, J. Phys. Chem. Solids, 2020, 139, 109326.

[6] Y. Tang, X. Zhang, Y. Ma, X. Wang, C. Su, D. Zhang, X. Pu, Y. Geng, Sep. Purif. Technol., 2020, 230, 115896.

[7] H. Tong, S. Ouyang, Y. Bi, N. Umezawa, M. Oshikiri, J. Ye, Adv. Mater., 2012, 24, 229-251.

[8] J. Low, J. Yu, M. Jaroniec, S. Wageh, A. A. Al-Ghamdi, Adv. Mater., 2017, 29, 1601694.

[9] B. Wang, Y. Ding, Z. Deng, Z. Li, Chin. J. Catal., 2019, 40, 335-342.

[10] P. Wang, S. Xu, F. Chen, H. Yu, Chin. J. Catal., 2019, 40, 343-351.

[11] Y. Li, Z. Jin, L. Zhang, K. Fan, Chin. J. Catal., 2019, 40, 390-402.

[12] X. Hao, Y. Hu, Z. Cui, J. Zhou, Y. Wang, Z. Zou, Appl. Catal. B, 2019, 244, 694-703.

[13] L. Shang, B. Tong, H. Yu, G. I. N. Waterhouse, C. Zhou, Y. Zhao, M. Tahir, L. Wu, C. Tung, T. Zhang, Adv. Energy Mater., 2016, 6, 1501241.

[14] M. Liu, L. Wang, G. Lu, X. Yao, L. Guo, Energy Environ. Sci., 2011, 4,

\section{Graphical Abstract}

Chin. J. Catal., 2021, 42: 439-449 doi: 10.1016/S1872-2067(20)63597-5

Coralline-like $\mathrm{Ni}_{2} \mathrm{P}$ decorated novel tetrapod-bundle $\mathrm{Cd}_{0.9} \mathrm{Zn}_{0.1} \mathrm{~S} \mathrm{ZB} / \mathrm{WZ}$ homojunctions for highly efficient visible-light photocatalytic hydrogen evolution

Zhuwang Shao, Xiao Meng, Hong Lai, Dafeng Zhang, Xipeng Pu*, Changhua Su, Hong Li, Xiaozhen Ren, Yanling Geng

Liaocheng University; Qingdao University of Science and Technology

$\mathrm{Ni}_{2} \mathrm{P}-\mathrm{Cd}_{0.9} \mathrm{Zn}_{0.1} \mathrm{~S}$ composites were synthesized by coupling tetrapod-bundle $\mathrm{Cd} 0.9 \mathrm{Zn}_{0.1} \mathrm{~S}$ and coralline-like $\mathrm{Ni}_{2} \mathrm{P}$ via a simple calcination method. The synergistic effects of the novel tetrapod-bundle morphology, ZB/WZ homojunctions, and decoration of the $\mathrm{Ni}_{2} \mathrm{P}$ co-catalyst can efficiently enhance visible-light photocatalytic hydrogen evolution.

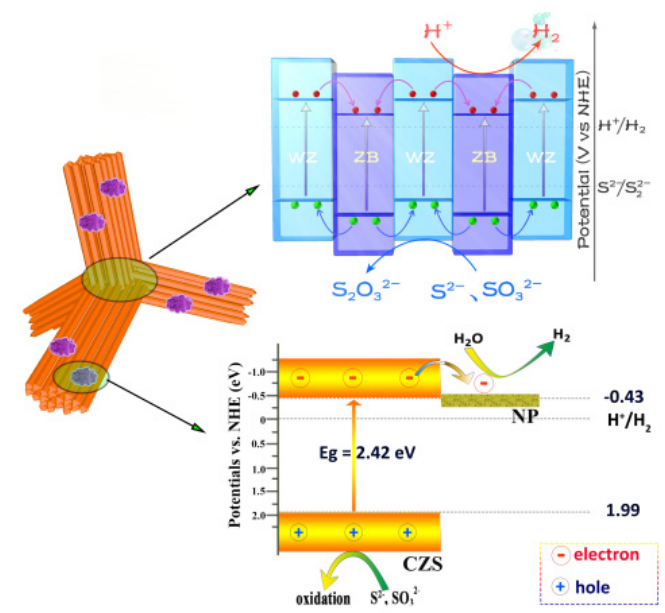


1372-1378.

[15] M. Liu, D. Jing, Z. Zhou, L. Guo, Nat. Commun., 2013, 4, 2278.

[16] J. Yu, Y. Yu, P. Zhou, W. Xiao, B. Cheng, Appl. Catal. B, 2014, 156-157, 184-191.

[17] J. Zhang, W. Li, Y. Li, L. Zhong, C. Xu, Appl. Catal. B, 2017, 217, 30-36.

[18] S. N. Guo, Y. L. Min, J. C. Fan, Q. J. Xu, ACS Appl. Mater. Interfaces, 2016, 8, 2928-2934.

[19] N. Bao, L. Shen, T. Takata, K. Domen, Chem. Mater., 2008, 20, 110-117.

[20] J. Jin, J. Yu, G. Liu, P. K. Wong, J. Mater. Chem. A, 2013, 1, 10927-10934.

[21] L. Yao, D. Wei, Y. Ni, D. Yan, C. Hu, Nano Energy, 2016, 26, 248-256.

[22] L. Ge, F. Zuo, J. Liu, Q. Ma, C. Wang, D. Sun, L. Bartels, P. Feng, J. Phys. Chem. C, 2012, 116, 13708-13714.

[23] Y. Xu, W. Zhao, R. Xu, Y. Shi, B. Zhang, Chem. Commun., 2013, 49, 9803-9805.

[24] F. Xue, W. Fu, M. Liu, X. Wang, B. Wang, L. Guo, Int. J. Hydrogen Energy, 2016, 41, 20455-20464.

[25] H. Du, K. Liang, C. Yuan, H. Guo, X. Zhou, Y. Jiang, A. Xu, ACS Appl. Mater. Interfaces, 2016, 8, 24550-24558.

[26] X. Chen, S. Shen, L. Guo, S. S. Mao, Chem. Rev., 2010, 110, 6503-6570.

[27] P. Zhao, Y. Li, L. Li, S. Bu, W. Fan, J. Phys. Chem. C, 2018, 122, 10737-10748.

[28] U. Caudillo-Flores, M. J. Munoz-Batista, M. Fernández-García, A. Kubacka, Appl. Catal. B, 2018, 238, 533-545.

[29] W. Ouyang, M. J. Munoz-Batista, A. Kubacka, R. Luque, M. Fernández-García, Appl. Catal. B, 2018, 238, 434-443.

[30] D. Gao, W. Liu, Y. Xu, P. Wang, J. Fan, H. Yu, Appl. Catal. B, 2020, $260,118190$.

[31] Y. Li, S. Yu, D.E. Doronkin, S. Wei, M. Dan, F. Wu, L. Ye, J. Grunwaldt, Y. Zhou, J. Catal., 2019, 373, 48-57.

[32] C. Guan, W. Xiao, H. Wu, X. Liu, W. Zang, H. Zhang, J. Ding, Y. P. Feng, S. J. Pennycook, J. Wang, Nano Energy, 2018, 48, 73-80.

[33] Y. Guo, P. Yuan, J. Zhang, H. Xia, F. Cheng, M. Zhou, J. Li, Y. Qiao, S. Mu, Q. Xu, Adv. Funct. Mater, 2018, 28, 1805641.

[34] C. Huang, C. Pi, X. Zhang, K. Ding, P. Qin, J. Fu, X. Peng, B. Gao, P. K.
Chu, K. Huo, Small, 2018, 14, 1800667.

[35] R. Wang, X. Y. Dong, J. Du, J. Y. Zhao, S. Q. Zang, Adv. Mater., 2018, 30, 1703711.

[36] Z. X. Qin, Y. B. Chen, Z. X. Huang, J. Z. Su, L. J. Guo, J. Mater. Chem. A, 2017, 5, 19025-19035.

[37] P. Xiao, W. Chen, X. Wang, Adv. Energy Mater., 2015, 5, 1500985.

[38] Y. Peng, L. Wang, Y. Liu, H. Chen, J. Lei, J. Zhang, Eur. J. Inorg. Chem., 2017, 2017, 4797-4802.

[39] Y. Chao, J. Zheng, H. Zhang, F. Li, F. Yan, Y. Tan, Z. Zhu, Chem. Eng. J., 2018, 346, 281-288.

[40] Y. Song, N. Li, D. Chen, Q. Xu, H. Li, J. He, J. Lu, Appl. Catal. B, 2018, 238, 255-262.

[41] R. Shen, J. Xie, X. Lu, X. Chen, X. Li, ACS Sustain. Chem. Eng, 2018, 6, 4026-4036.

[42] C. Han, T. Zhang, Q. Cai, C. Ma, Z. Tong, Z. Liu, J. Am. Ceram. Soc., 2019, 102, 5484-5493.

[43] W. Zhen, X. Ning, B. Yang, Y. Wu, Z. Li, G. Lu, Appl. Catal. B, 2018, 221, 243-257.

[44] D. Dai, L. Wang, N. Xiao, S. Li, H. Xu, S. Liu, B. Xu, D. Lv, Y. Gao, W. Song, L. Ge, J. Liu, Appl. Catal. B, 2018, 233, 194-201.

[45] D. Zeng, W. Xu, W. Ong, J. Xu, H. Ren, Y. Chen, H. Zheng, D. Peng, Appl. Catal. B, 2018, 221, 47-55.

[46] Y. J. Hsu, S. Y. Lu, Small, 2008, 4, 951-955.

[47] Z. Qin, F. Xue, Y. Chen, S. Shen, L. Guo, Appl. Catal. B, 2017, 217, 551-559.

[48] W. Wang, T. An, G. Li, D. Xia, H. Zhao, J. C. Yu, P. K. Wong, Appl. Catal. B, 2017, 217, 570-580.

[49] T. Di, B. Cheng, W. Ho, J. Yu, H. Tang, Appl. Surf. Sci., 2019, 470, 196-204.

[50] Y. Tang, D. Zhang, Y. Li, B. Huang, H. Li, X. Pu, Y. Geng, Sep. Purif. Technol., 2019, 220, 78-88.

[51] W. Yu, J. Chen, T. Shang, L. Chen, L. Gu, T. Peng, Appl. Catal. B, 2017, 219, 693-704.

[52] X. J. Wen, C. G. Niu, D. W. Huang, L. Zhang, C. Liang, G. M. Zeng, J. Catal., 2017, 355, 73-86.

[53] S. Peng, Y. Yang, J. Tan, C. Gan, Y. Li, Appl. Surf. Sci., 2018, 447, 822-828.

[54] P. Wang, Y. Lu, X. Wang, H. Yu, Appl. Surf. Sci., 2017, 391, 259-266.

\title{
珊瑚状 $\mathrm{Ni}_{2} \mathrm{P}$ 修年新型四足状 $\mathrm{Cd}_{0.9} \mathrm{Zn}_{0.1} \mathrm{SZB} / \mathrm{WZ}$ 同质结光催化剂的高效 可见光光催化产氢
}

\author{
郡珠旺 ${ }^{\mathrm{a}}$, 孟 晓 ${ }^{\mathrm{a}}$, 赖 红, 张大凤 ${ }^{\mathrm{a}}$, 蒲锡鹏 ${ }^{\mathrm{a},{ }^{*}}$, 苏昌华 ${ }^{\mathrm{a}}$, 李 红, 任小珍 ${ }^{\mathrm{a}}$, 耿延玲 ${ }^{\mathrm{b}}$ \\ a聊城大学材料科学与工程学院, 化工能源存储与新型电池技术山东省重点实验室, 山东聊城252000

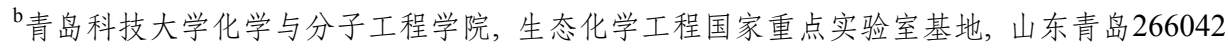

\begin{abstract}
摘要: 随着社会发展, 传统化石能源消耗加剧, 人类迫切需要开发新型的清洁能源. 半导体光催化分解水产氢是一种非常 具有潜力解决能源危机的清洁技术. 目前, 金属硫化物半导体有着合适的能带结构和高效的光催化产氢能力而得到了广 泛的研究. 通常, 为了提高光催化剂产氢性能, 添加贵金属助催化剂是一个行之有效的方法. 但是贵金属昂贵的价格限制 了其大规模的应用, 因此有必要研究储量丰富, 价格低廉的高效助催化剂. $\mathrm{Ni}_{2} \mathrm{P}, \mathrm{CoP}, \mathrm{Co}_{2} \mathrm{P}, \mathrm{MoP}, \mathrm{Cu}_{3} \mathrm{P}$ 等过渡金属磷化物 具有价格低廉, 优异的稳定性和催化性能而被用作电催化产氢的催化剂. 通常, 用于电催化产氢的催化剂往往可以作为光 催化产氢的助催化剂.

众所周知, 催化性能与材料的形貌密切相关, 因此, 具有棒状、中空、片状等形貌的金属硫化物被制备并用于光催化产 氢. 然而, 四足状结构的金属硫化物研究较少. 在已有的 $\mathrm{Ni}_{2} \mathrm{P}(\mathrm{NP})$ 相关研究中, 仅合成了纳米颗粒状的NP. 本文成功合成 了四足状 $\mathrm{Cd}_{0.9} \mathrm{Zn}_{0.1} \mathrm{~S}(\mathrm{CZS})$ 和珊瑚状形貌的 $\mathrm{NP}$, 进一步得到一系列 $\mathrm{Ni}_{2} \mathrm{P}-\mathrm{Cd}_{0.9} \mathrm{Zn}_{0.1} \mathrm{~S}$ (NPCZS) 光催化剂, 采用XRD, SEM, TEM, XPS和ICP-AES测试了样品的结构、形貌、表面成分和元素含量.并测试了样品的光催化产氢性能.
\end{abstract}


采用水热法合成的CZS样品具有特殊的四足状形貌, 足部由纳米棒组成. XRD结果表明, 四足状CZS中立方相(WZ)和 六方相(ZB)共存. 经TEM进一步分析, 发现CZS中心部位呈ZB相结构, 而足部却是WZ相. 经光催化性能测试, 这种新型四 足状CZS表现出优异的光催化产氢性能. 进一步通过超声或研磨破坏四足状结构后, 发现CZS的产氢性能显著下降, 说明 四足状形貌是材料性能提高的关键. 通过分析WZ和ZB两物相的价带顶和导带底的电位发现, ZB/WZ间形成的同质结可以 加速光生载流子的分离和传输. NP也采用水热法制备, 其具有珊瑚状形貌. 该形貌具有高的比表面积, 可以提供更多的活 性位点, 进一步提高了材料的光催化性能.

光催化性能测试表明, NP负载量为 $12 \mathrm{wt} \%$ 的NPCZS-12样品表现出很好的产氢性能 $\left(1.88 \mathrm{mmol} \mathrm{h}^{-1}\right)$, 是纯CZS的1.43倍. 同时, NPCZS-12具有良好的光稳定性和循环使用性能. 结合光催化实验、光谱实验、表面光电压和电化学测试的结果发现, 四足状形貌、同质结和NP助催化剂的协同效应是NPCZS具有良好光催化性能的主要原因.

关键词: 光催化产氢; $\mathrm{Cd}_{0.9} \mathrm{Zn}_{0.1} \mathrm{~S} ; \mathrm{Ni}_{2} \mathrm{P}$; 同质结; 无贵金属

收稿日期: 2020-05-20. 接受日期: 2020-06-28. 出版日期: 2021-03-05.

*通讯联系人. 电话: (0635)8230915; 电子信箱: xipengpu@hotmail.com

基金来源：山东省自然科学基金(ZR2018MEM019).

本文的电子版全文由Elsevier出版社在ScienceDirect上出版(http: //www.sciencedirect.com/science/journal/18722067). 